DOI: 10.17805/ggz.2019.1.8

\title{
О проблемах изучения смысловой организации культуры
}

\author{
С. В. Горюнков
}

НИЦ «Методологический переформат», г. Санкт-Петербург

В статье рассмотрено важнейшее для создания полноценной теории культуры понятие «смысловая реальность». Показано, что изучение этой реальности должно начинаться с различения в естественном языке двух его относительно-самостоятельных составляющих: практического языка, обслуживающего элементарные потребности выживания и общения, и символического языка, отвечающего за отвлеченное мышление. Проанализированы структура, историческая динамика и функциональная специфика символического языка, отличающие его от практического. Дана модель функиионирования символического языка, «пульсирующего» между полисемической и относительно однозначной формами своей смысловой организаџии.

Отмечена главная особенность символического языка: с внеязыковой реальностью он соотносится не поэлементно, как практический язык, а всей своей смысловой полнотой и целостностью. Раскрыта прямая связь этой особенности символического языка с методологической проблемой «круга понимания». Показано, что решение проблемы «круга» связано с необходимостью радикального пересмотра теории происхождения культуpbl.

Ключевые слова: смысловая реальность; практический язык; символический язык; диалогический аппарат; пульсирующая культура; кризис понимания; проблема «круга»

\section{On the Problems of Studying the Semantic Organization of Culture}

\author{
S. V. Goryunkov \\ Research Centre "Methodological Reformat", \\ St. Petersburg
}

The article deals with the concept of "semantic reality" that is the most important for the creation of a full-fledged theory of culture. It is shown that the study of this reality should begin with a distinction between its two relatively independent components in the natural language: the practical language serving the basic needs for survival and communication, and the symbolic language responsible for abstract thinking. The author analyzes the structure, historical dynamics and functional specificity of the symbolic language distinguishing it from the practical one. He presents a model of the functioning of the symbolic language that 
"pulsates" between the polysemic and relatively unambiguous forms of its semantic organization.

The main feature of the symbolic language is noted: it is correlated with nonlinguistic reality not element-by-element (as the practical language is), but by all its semantic completeness and integrity. The direct connection of this feature of the symbolic language with the problem of the "circle of understanding" is revealed. It is shown that the solution of the "circle" problem lies in the need for a radical revision of the theory of the genesis of culture.

Keywords: semantic reality; practical language; symbolic language; dialogical apparatus; pulsating culture; crisis of understanding; problem of "circle"

\section{ВВЕДЕНИЕ}

Цель настоящей статьи - определиться с базовыми принципами смысловой организации культуры в ее исторической динамике и функциональной специфике. Будучи междисциплинарной сверхзадачей, такая цель видится как построение общей связной картины смысловой реальности. О чем напоминает, в частности, Д. А. Леонтьев: «...необходимо прежде всего попытаться содержательно понять специфическую природу и онтологию смысловой реальности как реальности особого рода» (Леонтьев, 2007: 104).

Но достижению цели с самого начала препятствует недостаточная освоенность проблематики, связанной с понятием «смысла». Если в отдельных областях научных исследований (в психологии, логике, науках о языке и мышлении) данное понятие уже давно и активно обсуждается, то об истории культуры, ответственной, казалось бы, за собирательное понимание феномена «смысла», этого не скажешь. Что не удивляет: здесь до сих пор не ясна граница, разделяющая людей и животных (культуру и природу).

Где эта граница пролегает? И почему ее интерпретации так противоречивы?

В историко-материалистической картине мира за нее принят, как известно, исторический период, отделивший людей современного вида от их обезьяноподобных предков: «...протекли сотни тысяч лет, — в истории Земли имеющие не большее значение, чем секунда в жизни человека, — прежде чем из стада лазящих по деревьям обезьян возникло человеческое общество» (Энгельс, 1982: 148). И так же она продолжает восприниматься сегодня, разве что чаще говорится о ее размытости. Как утверждает Вяч. Вс. Иванов, «в животном мире уже можно увидеть нечто, что напоминает нашу интеллектуальную, а, может быть, даже и духовную деятельность» (Иванов, 2004: 54). В особенности это относится к млекопитающим: «Некоторое время назад был целый бум в связи с китами и дельфинами. Много писали о том, что по устройству мозга и по другим параметрам их можно отнести к мыслящим существам...» (там же: 58). Что касается приматов, то во второй половине $\mathrm{XX}$ века появилось много работ, показавших способность человекообразных обезьян, в условиях их общения с человеком, выполнять «значительное число интеллектуальных и семиотических, в частности лингвистических задач, сопоставимых с человеческими» (там же: 59-60). 
Одновременно наблюдается и обратная идее размытости границы тенденция, заостряющая внимание на моменте внезапности перехода из одного состояния к другому. Эту тенденцию зафиксировала Т. В. Черниговская: «Есть все жители этой планеты, потом есть некий провал. И тогда начинается человек» (Черниговская, 2008: Электронный ресурс). Но «провал» у нее вовсе не отказ от представления о едином эволюционном процессе: «...я сейчас не скажу, что человек - это существо семиотическое, а остальные нет. Просто мы изощренней. Но никакого разрыва между нами нет» (там же). T. е. обратная тенденция исходит из понимания эволюции не как постепенного направленного процесса, а как бесцельной непредсказуемой самоорганизации, допускающей нарушения постепенности (там же). При этом обе тенденции сходятся в главном: в признании того, что граница между людьми и их звероподобными предками (неважно, растянутая во времени или относительно мгновенная) - в степени, а не в качестве.

Есть версия, заостряющая внимание именно на качестве границы, разделяющей людей и животных. Эту версию, основанную на критике термина «естественный язык», выдвинул В. И. Абаев: «Если слова имеют еще какойнибудь смысл, то “естественное” в применении к человеку может означать только “биологическое" и ничего более. Надо быть крайне неразборчивым в употреблении терминов, чтобы языки Гомера, Фирдоуси, Данте, Шекспира, Пушкина называть “естественными”, т. е. явлением биологического уровня. Элементарной истиной является то, что язык возникает не на биологическом, а на социальном уровне. Это справедливо как в онтогенетическом плане (в развитии индивида), так и филогенетическом плане (в развитии человечества в целом). <..> Странно и парадоксально называть “естественным” то, что было первейшим признаком преодоления естественного, - язык» (Абаев, 1976: 77).

Наконец, есть и еще один вариант ответа на вопрос о границе между языками людей и животных. Он основывается на высказанной Нильсом Бором идее, согласно которой человек отличается от животных не мыслительной деятельностью вообще, а лишь тем ее аспектом, который ответственен за оперирование понятиями. «Четкую границу между человеком и животным, - писал Н. Бор, - нельзя было бы провести даже и по признаку способности передавать информацию от одной особи к другой...» (Бор, 1961: 45). Но «никакое настоящее человеческое мышление невозможно без употребления понятий... < ..> Новорожденного ребенка едва ли можно считать человеческим существом именно потому, что он еще не пробудился для пользования понятиями...» (там же: 45-46).

По этому четвертому варианту обсуждаемая граница пролегает не между языками животных и человеческим языком, а внутри самого «естественного языка» - универсального, по Э. Бенвенисту, интерпретанта любых семиотических проявлений культуры (кавычки применительно к термину «естественный язык» указывают на то, что его критика В. И. Абаевым вполне оправданна). 


\section{ПРАКТИЧЕСКИЙ И \\ СИМВОЛИЧЕСКИЙ ЯЗЫКИ}

Четвертый вариант означает, что в «естественном языке» скрыто присутствуют два относительно самостоятельных, но при этом тесно взаимодействующих друг с другом языка: тот язык, который роднит людей с животными, и тот, который делает людей причастными культуре.

Чтобы лучше понять, о каких конкретных языках идет речь, посмотрим, на какие темы «разговаривает» обезьяна. Она, оказывается, может сказать (на языке жестов и/или предметных знаков) «дай мне пить», «почеши мне спину» и даже обозвать не нравящегося ей человека «грязным». Но ни одна обезьяна в процессе обучения так и не смогла достичь уровня, начиная с которого с ней можно было бы поговорить, например, о философии, литературе или политике. И дело не в том, что существует «потолок» в количестве запоминаемых обезьяной слов; существование такого «потолка» никто еще не доказал. Дело в качестве слов - в различии между знаками, отсылающими к тем или иным сторонам внеязыковой реальности, и знаками, отсылаюшими к другим знакам (Горюнков, 2017: 19).

Сущность второй категории знаков - предельно широко понимаемый символизм (знаковое выражение чего-либо, наделенное переносным содержанием). Сравним, например, просьбу обезьяны «дай мне пить» с аналогичной просьбой, описанной в Евангелии от Иоанна (Ин. 4: 7-10). При всем внешнем сходстве обеих просьб очевидно, что обе они выражены на разных языках: на том, который принято называть «практическим» (сообщающим «нечто, имеющее практический смысл» - Иванов, 2004: 56), и на том, который уместно, вслед за В. И. Абаевым, назвать «символическим»: «...условный, символический характер языкового знака... сближает человеческий язык с любыми другими символическими знаковыми системами и отделяет пропастью от естественного языка животных» (Абаев, 1976: 79).

Но и пропасть, вопреки В. И. Абаеву, условна, потому что практический язык представлен не только невербальным языком природы, но и вербально-артикулированным языком культуры, выполняющим в ней функцию «моста» между обоими языками. Во второй своей роли он, решительно преобладая над символическим языком в повседневной речевой практике, обслуживает те потребности людей, которые являются потребностями их выживания и общения. А с языком культуры его сближает общий лексический фонд - строительный материал для конструкций символического языка. Поэтому во второй своей роли он оказывается необходимейшей предпосылкой и условием существования культуры.

\section{ФОРМЫ ПРЕДСТАВЛЕНИЯ ЯЗЫКОВ}

Сама по себе идея совмещения в «естественном языке» двух его составляющих не нова, - она отчетливо прослеживается уже в древнейших культурах, где современному понятию «языкового сознания» предшествовало понятие «души» - донаучное представление об устройстве внутреннего мира личности. Согласно этому представлению, указанный мир состоит из 
двух функиионально различных душ (часто - при номинально большем их количестве), где одна отвечает за утилитарные интересы и потребности личности, а другая - за все, что выходит за их пределы. Например, в Древней Индии такими душами считались «атман» (индивидуальная душа, субъективное духовное начало, «я») и «брахман» (высшая реальность, духовная основа бытия, универсальное творческое начало). Их соответствия: в Древнем Китае - «по» и «хунь», в Древнем Египте - «ба» и «ка», в Древней Греции - «психэ» и «пневма». Славянский аналог тех же понятий - «душа» и «дух», что видно из пословицы «дух на небо иде (по смерти. - С. Г.), а душа в землю», где и «згнивае» (Славянские ..., 1999: 162).

В христианстве языческое различение «души» и «духа» хотя и сохранилось, но с модернизированной трактовкой души как частицы бессмертного духа; древняя же суть взаимоотношения понятий продублирована другим различением: «буквы» и «духа» (2 Кор., 3: 6) Наука тоже пошла по пути дублирования древней сути: уже в XVI веке поводом для различения качества языковых высказываний послужило разграничение Маттиасом Флациусом Иллирийским «значений» и «смыслов», закрепленное позднее в логикоматематических трудах Г. Фреге (Леонтьев, 2007: 9-10). Наметились и другие разграничительные линии. Например, в философии говорится о «чувственном» и «абстрактном» познании, в семиотике - о «первичных» и «вторичных» знаковых системах (к ним еще вернемся), в вероятностной теории смыслов - о «дискретных» и «континуальных» текстах (Налимов, 2011: 143). И нужно быть законченным «рабом буквы» - рабом вырванных из контекста «значений», чтобы за многообразием всех таких смысловых различий не увидеть частных проявлений одного и того же принципа.

\section{СТРУКТУРА ЯЗЫКОВ}

Принцип этот вовсе не означает, что языки подлежат формальному разделению - оно невозможно уже потому, что одни и те же слова могут служить элементами как практического, так и символического языков. Рeально языки подлежат не разделению, а различению по целому ряду параметров, в первую очередь структурных.

Структурное различие между языками выглядит следующим образом: практический язык в его вербально-артикулированной форме - это механическая сумма разрозненных словесных знаков, сообщающих нечто, отсылающее к той или иной однозначно понимаемой конкретности и связанное с удовлетворением элементарных потребностей. Высшая форма его структурной организации - это лексические комбинации, выстраиваемые с целью максимально эффективного обеспечения коммуникативной функции. Образно говоря, практический язык - это «мешок со словами»: доставай их из мешка и, комбинируя по ситуации, общайся. Его слова не связаны друг с другом теми дополнительными смысловыми отношениями, которые делают язык многомерной семантической конструкцией, инструментом моделирования мира. 
Символический же язык устроен как взаимосвязанная смысловая структура, знаки которой, повторюсь, обретают смысл через их соотнесение не с отдельными сторонами внеязыковой реальности, а с другими знаками. Конкретно это выглядит так: представим себе, что мы хотим узнать смысл некоего понятия. Для этого мы берем в руки толковый словарь и находим соответствующую словарную статью, разъясняющую смысл понятия. Но словарная статья тоже состоит из понятий, к каждому из которых тоже можно подобрать словарную статью. А новые словарные статьи тоже содержат в себе понятия, раскрываемые через новые словарные статьи. И если продолжать данный процесс достаточно долго, то все окончится исчерпанием словарного запаса символического языка и подтверждением того факта, что «смысловые образования не существуют изолированно, а образуют единую систему» (Леонтьев, 2007: 104).

Речь идет о той единой системе, которая описывается посредством лексико-семантических словарей - тезаурусов. Такие словари принято рассматривать как инструменты представления знаний об универсуме и его отдельных предметных областях. Они строятся в форме иерархии семантических полей, кодирующих смысл слов через родо-видовые (видо-родовые) отношения между ними. Идея таких совмещенных с алфавитными словарей лежит в основе построения информационно-поисковых языков, библиотечного каталогизирования, составления специализированных энциклопедий (Принципы ... , 1976: 313-340) ${ }^{1}$.

Что касается сознания личности или общественной группы, то здесь тезаурус принимает вид классификации знаний о мире в соответствии с представлениями личности (группы) об их важности для достижения своих целей. Такой тезаурус оказывается эклектической конструкцией из разнородных представлений о мире, смесью их редуцированных фрагментов и обрывков. Но при всей эклектичности в нем всегда присутствует «смысловое ядро»картина мира (не обязательно одна) как наиболее устойчивая часть тезауруса (Луков В., Луков Вл., 2008: 12-62, 90-96).

Важный момент: высказывания, делаемые на языке «смыслового ядра» - это «верхушки айсбергов», смысловых слоев, обеспечивающих предпосылочную основу высказываний. Т. е. у каждого высказывания есть некая более широкая предпосылка, в которую высказывание встроено как следствие из нее. У этой предпосылки есть еще более широкая предпосылка, а у более широкой - еще более широкая и т. д. - вплоть до предельно общего представления о мире как о целостной системе. Так уж устроена иерархическая структура тезауруса, почему и возможна логика - техника выведения следствий из их предпосылок (Горюнков, 2014: 139).

Без учета этой предпосылочной структуры, задающей сущностно значимую иерархию высказываний, любой обмен мнениями превращается или в склочное препирательство о словах, или в «глухариное токование» каждого о своем, или в устроенное с коммерческой (идеологической и др.) целью шоу,

\footnotetext{
${ }^{1}$ См. вклейку со схемой словаря Р. Халлига и В. Вартбурга в конце книги.
} 
или в инструмент сознательного забалтывания «неудобных» тем. Или же он превращается в политтехнологию формирования общественного мнения, заранее назначенного на роль «единственно правильного».

\section{ИЗДЕРЖКИ НЕРАЗЛИЧЕНИЯ ЯЗЫКОВ}

Неразличение практического и символического языков сопровождается обычно рядом издержек. Например, восприятие «социализма», «капитализма», «демократии», «монархии» и т. п. как вербальных отражений неких конкретных сущностей делает людей «рабами слов» (Горюнков, 2013). Когда политтехнологи, подобно персонажам басни И. А. Крылова «Квартет», предлагают людям сесть то «по-социалистически», то «по-капиталистически», то «по-демократически», то «по-монархически», - они по факту занимаются сведением символического языка к практическому, потому что слова «социализм», «капитализм», «демократия», монархия» не содержат в себе ничего однозначного. Достаточно вспомнить про шведский и швейцарский «социализмы», или про нэповский и китайский «государственные капитализмы», или про то, что «демократия», по А. С. Пушкину, всего лишь произвольно толкуемое слово (Смирнова-Россет, 2003: 297), или про то, что бутафорский характер английской монархии был ясен еще Ивану Грозному: «Мы надеялись, - писал царь королеве Елизавете, — что ты в своем государстве государыня. <..> Но, видно, у тебя, помимо тебя, другие люди владеют, и не только люди, а мужики торговые, и не заботятся о наших государских головах и о чести и о выгодах для страны, а ищут своей торговой прибыли» (Памятники ..., 1986: 113, 115).

Продолжая аналогию с персонажами басни Крылова, нужно будет признать, что «музыка человеческих отношений», т. е. качество духовной жизни общества, зависит не от способа сидения «музыкантов», а от наличия или отсутствия у них такой категории символического языка, как «совесть». Но когда те же политтехнологи (социалистические, капиталистические, демократические или монархические - не имеет значения), подобно персонажу другой крыловской басни «Кот и повар», призывают людей к совести, они опятьтаки занимаются сведением символического языка к практическому. Потому что совесть - не самодостаточная сущность, которую можно вставить в общественное сознание наподобие компакт-диска в компьютер, а производное от мировоззрения, несущего в самом себе ответ на вопрос: почему я должен считаться не только со своими, но и с чужими интересами?

Мировоззрение (явленная в тезаурусе взаимосвязь понятий) и есть та форма существования символического языка, смысловым устройством которой определяется наличие или отсутствие в сознании его носителей любых ценностных аспектов культуры, в том числе и совести. Проблема лишь в том, что само смысловое устройство этого языка определяется не только его структурной организацией, но и его изменчивостью во времени - его исторической динамикой. 


\section{ИСТОРИЧЕСКАЯ ДИНАМИКА}

Задача построения универсального общеязыкового тезауруса до сих пор далека от своего решения, и не только в силу необычайной сложности смысловой структуры символического языка. Дело еще и в его исторической динамике, говорить о которой приходится сегодня не как об уточнениях и дополнениях к чему-то окончательно решенному, раз и навсегда установленному, а как о предмете, с которым связана масса разногласий и просто сомнительных утверждений.

Взять хотя бы тот вариант различения практического и символического языков, который в семиотике представлен «первичными» и «вторичными» знаковыми системами. Известно, что сами эти термины - чисто условные, никаким эмпирическим материалом не оправданные. Они были предложены представителями московско-тартуской семиотической школы, во-первых, с целью избежать частого употребления термина «семиотика», вызывавшего неприятие со стороны официальной идеологии (Кармин, 2011: 65, примечание), а во-вторых - с целью объяснить их различие эволюционноисторическим контекстом. Согласно второй цели, первичные средства культуры развиваются путем самоусложнения до уровня своих вторичных форм (там же: 65). Но поскольку реальной границы между ними на хронологической «шкале самоусложнения» найти невозможно, потому что нет и самой придуманной шкалы - вульгарно-механистической схемы развития «от простого к сложному, от низшего к высшему», то она произвольно постулируется. А произвольным постулатом создается почва для дальнейших, столь же произвольных умозрений вроде термина «естественный язык» и прочих вытекающих из него теоретизмов.

Более серьезного внимания заслуживают совсем другие, эмпирически оправданные, модели исторической динамики языка культуры. Например, такие, как модель перевода бессознательно-мифологических форм коллективного мышления в их осознанно-рефлексивные формы (Г. Юнг), или модель преобразования символов-образов в символы-понятия (О. М. Фрейденберг), или модель «трансформации инварианта» (В. В. Иванов, В. Н. Топоров). Или же модели «диалога», от теорий типа «вызов - ответ» (А. Тойнби) до взгляда на взаимодополняемость мировых цивилизаций как на основу и решающий фактор социальной динамики (Мировой.., 2013: Электронный ресурс). А среди диалогических моделей особый интерес представляют те их варианты, которые рассматривают диалог с позиции высших ценностей (М. М. Бахтин).

Общим для эмпирически оправданных моделей является присущая им по факту семантическая сложность, в свете которой историческую динамику символического языка приходится объяснять уже не механическим наращиванием его смыслового объема, а критической рефлексией над его изначально сложными формами и, как следствие, перманентным перебором его внутренних смысловых связей (Горюнков, 2016: 201). В свою очередь, такой перебор объясняет, почему мифы - древнейшие формы смысловой организации символического языка — производят на современных людей впечатле- 
ние «абсурдных россказней» (Леви-Стросс, 1978: 100-101). И он же объясняет, почему любые постмифологические формы символического языка всегда несут на себе следы мировоззренческой специфики древних эпох, «родимых пятен» ее смыслового поля, ее неповторимого речестроя.

\section{ГЕРМЕНЕВТИЧЕСКИЙ АСПЕКТ}

Объясняется перебором смысловых связей и причина, по которой «современная гуманитарная наука по существу есть герменевтика - наука об истолковании текста» (Колесов, 1998: 207). Причина эта — в отмеченной еще русским богословом XVI века исторической изменчивости языковых смыслов: «...сказанное разными людьми в разное время об одном и том же предмете имеет различный смысл» (Преподобный ... , 1993: 131). И на ту же изменчивость все чаще обращается внимание сегодня: «На разных этапах и в различных исторических условиях одни и те же понятия могли менять свое содержание» (Луков, 2008: Электронный ресурс).

Вот наглядный пример смысловой изменчивости понятий в большом историческом времени: судя по мему «истина одна, а правд много» («у каждого своя правда»), «истина» считается сегодня понятием намного более содержательным, чем «правда». Но встарь понятием «истины» и производными от него формами («истота», «истовина», «истовик») удостоверялось соответствие истины не познавательному идеалу, а конкретной предметности (Даль, 1996: 60). В частности, под «истиной» понималась «наличность», «наличные деньги»; «истиник» - «капитал», «чистоган» (там же). «Правда» же, судя по древнерусскому написанию этого слова в форме «правьда», означала данную свыше «пра́-веду» - вещее знание о мире. Она действительно мыслилась в русской языковой традиции чем-то вроде духовного маяка или компаса, о чем свидетельствуют речевые обороты «святая правда», «божья правда», «правда не судима», «правда глаза колет», «все минется, а правда останется».

Отсюда - пережиточно сохраненный в Псалтири языческий архаизм: «истина от земли возсия, и правда с небесе приниче» (Пс. 84; 11-12). Из него видно, что в древности смысловой связью понятий «истины» и «правды» дублировалась связь понятий «души» и «духа» (см. выше: «дух на небо иде, а душа в землю») Чем лишний раз доказывается фундаментальность различения двух составляющих внутреннего мира личности.

\section{ПРОБЛЕМА ПОЛИСЕМИИ}

Изначальной сложностью символического языка обусловлена и та его специфика, согласно которой одно и то же слово, употребленное в различных семантических контекстах, может наполняться совершенно разным смысловым содержанием. Специфика эта, называемая полисемией, просто и наглядно объясняет, что смысл слова - не «атомарное» его свойство, а производное от связей слова с другими словами.

С полисемией мы сталкиваемся уже в древнейших тезаурусах — в мифологических формах организации символического языка. Так, персонажи мифов - это одновременно и непосредственные предки людей, и персони- 
фикаторы абсолютно всего: от природных явлений, а также различных животных и растений до предметов материальной и проявлений нематериальной культуры. В сущности, вся последующая эволюция коллективного мышления сводится к попыткам избавления от этой древнейшей полисемии, чем и объясняется разнообразие постмифологических форм проявления культуры: фольклора, религии, философии, искусства, науки, литературы и др. Но поскольку становление такого разнообразия неотделимо от вышеупомянутого перебора смысловых связей внутри символического языка, то и попытки избавления от полисемии всегда, по большому счету, тщетны. А там, где они оказываются временно-успешными (о чем еще будет сказано), полисемия продолжает жить в своих вырожденных лексико-семантических проявлениях: в метафорах, метонимиях и т. д.

Единого понимания сущности полисемии сегодня нет. И понятно, почему, - ведь доступной настоящему изучению она становится лишь в свете различения практического и символического языков.

\section{ВЛАСТЬ НАД СОЗНАНИЕМ}

Всем вышесказанным исчерпывающе объясняются слова С. С. Аверинцева о символологии как «инонауке» (Аверинцев, 2001: 157): в них угадывается отсылка к давно присутствующей в ментальном поле науки, но до сих пор никем не обсуждаемой и, соответственно, никак не решаемой методологической проблеме.

Действительно: ни иерархическая структура замкнутого в себе символического языка, ни его изначальная, внутренне-изменчивая сложность никак не вписываются в привычную истматовскую аксиоматику. Не вписывается в нее и тот факт, что речевой процесс на практическом и символическом языках - совершенно разные вещи. В первом случае мы являемся хозяевами своих слов; во втором случае наша власть над ними иллюзорна. На второй случай обратил внимание В. И. Вернадский: «Бывает так, когда понимаешь, а передать, сказать, сообщить другим не можешь...» (Страницы ... , 1981: 134). Как следствие, мы начинаем догадываться, что наше сознание находится под «колпаком» языкового тезауруса - взаимосвязанной системы смысловых структур ориентирующего характера (Луков В., Луков Вл., 2006). Мы обнаруживаем, что язык - это не деятельность и не функция, а нечто сравнимое с ограничительной «сеткой знаков, как бы наброшенной на наше поле восприятия, деятельности, жизни» (Рикер, 1995: 380). Мы начинаем осознавать, что «язык есть способ мироистолкования, предпосланный любому акту рефлексии», что «мышление всегда движется в колее, пролагаемой языком» и что «языком заданы как возможности мышления, так и его границы» (Гадамер, 1991: 24).

Не вписываются в указанную аксиоматику и следующие высказывания М. Хайдеггера: «...мы, люди, чтобы быть тем, что мы есть, встроены в язык и никогда не сможем из него выйти» (Хайдеггер, 1993: 272); «Мы говорим не только на языке, мы говорим от него» (там же: 266; курсив источника. C. Г.); «Мы слышим, как язык - говорит» (там же). О том же - у Х.-Г. Га- 
дамера: мы находимся внутри языкового «предания», с помощью которого осознаем себя в мире (Гадамер, 1988: 335); аналогично у М. Элиаде: «...мир раскрывает себя как язык» (Элиаде, 2000: 136). По М. М. Бахтину, человек «отброшен в мир бесконечно требовательного смысла» (Бахтин, 1986: 115); по В. В. Налимову, он «существует лишь в той мере, в какой он погружен в мир смыслов» (Налимов, 1989: 247).

Иными словами: не люди говорят языком (на языке) символических смыслов, а сам он говорит людьми (в людях). Он в полном смысле слова властвует над человеческим (как индивидуальным, так и массовым) сознанием.

\section{БРЕМЯ КУЛЬТУРЫ}

Власть символического языка над человеческим сознанием - это одно из проявлений скрыто-программирующей функции культуры (Горюнков, 2014: 100), много объясняющей, кстати, в популярной сегодня, но маловразумительной по сути риторике о «ментальной свободе» и «духовном рабстве». Действительно, власть языка над сознанием не может не ощущаться этим сознанием как ограничение его свободы, - чем и объясняется определение культуры как несвободы, то есть как системы ограничений, налагаемых на вседозволенность (А. Х. Пуртинга). Отсюда - замеченное А. С. Пушкиным бремя несения культуры: «...все мы несем бремя жизни, иго нашей человечности, столь слабой, столь подверженной заблуждению...» (Смирнова-Россет, 2003: 318). Отсюда же - «недовольство / неудовлетворенность культурой» (Фрейд, 2007), «усталость от культуры» (Кабыш, 2007: 13), «бегство от культуры» (Зелинский, 2008: 72-75) и прочие им подобные метафоры одного и того же явления.

Явление это уместно назвать утратой смысла несения бремени кульmуры (Горюнков, 2014: 300-301), или - что то же самое - утратой смысла жизни. А вопрос о таком смысле тоже объясняется спецификой символического языка, потому что сводится в конечном счете к вопросу о смысле самого этого языка. Что и начинает осознаваться: с точки зрения М. Полани, «мы должны понять, что последним основанием наших убеждений является сама наша убежденность, вся система посылок, логически предшествующих всякому конкретному знанию» (Полани, 1985: 278; цит. по: Налимов, 2011: 210).

Осознание данного факта - это все то же, но выраженное другими словами осознание континуального характера символического языка как «замкнутого в себе космоса» (Кассирер, 2002: 20).

\section{ЯЗЫКОВАЯ ИНОСКАЗАТЕЛЬНОСТЬ}

Выражение «другими словами» указывает на принципиальноиносказательную - кодовую - сущность символического языка.

Данную сущность принято обычно рассматривать как одну из частных функций языка, в частности - как его литературное украшательство. Вместе с тем предпринимаются и попытки взглянуть на иносказательность более широко: как на свойство человеческого мышления «связывать вещи, явления, 
события между собой и таким образом наделять их иным по отношению к ним самим значением (смыслом). Такое широкое понимание иносказания раздвигает и спектр результатов иносказательного процесса - теперь это не только отдельные поэтические фрагменты текста или любое новое значение, воплощенное в слове или высказывании, это также многочисленные социально-психологические и социокультурные феномены, материальные и духовные ценности, образующие человеческую культуру» (Трунов, 2000: 17).

Такой взгляд на иносказательность позволяет понять ее как одну из форм существования символического языка. А все многообразие видов иносказательности сводится при таком ее понимании к двум основным классам: к тому, в котором об одном и том же говорится по-разному, и к тому, в котором говорится об одном, а смыслы в сказанном скрываются / открываются другие. Оба класса взаимно дополняют друг друга, - ведь в том и заключается искусство употребления uнblх слов, что с их помощью облегчается или, наоборот, затрудняется восприятие получаемой информации. Например: притчевая иносказательность евангельских текстов, использующая принцип уподобления одних ситуаций другим, делает тем самым более доходчивыми идеи повышенной социальной значимости. Или: высший класс манипулирования сознанием сводится к тому, чтобы, не называя вещи своими именами (т. е. называя их другими именами), навязать объекту манипуляций скрыто содержащуюся в них установку.

\section{КРИТЕРИЙ СМЫСЛОВОЙ ПОЛНОТЫ}

Всякая иносказательность начинается, повторимся, с необходимости сказать о чем-либо другими словами. При этом конкретика других слов, практически необозримая, может быть заменена отсылкой к смысловой полноте всего символического языка.

Показать это легче всего на понятиях, считающихся в системе рационального знания «относительными» - на понятиях «добра» и «зла». Дело в том, что, будучи используемыми в роли элементов практического языка, эти понятия и вправду производят впечатление «относительных» (или демагогических, как в политическом жаргоне: «империя добра», «империя зла»). Но совсем иначе они начинают выглядеть в контексте своей символической функции, раскрытой Дионисием Ареопагитом с опорой на критерий смысловой полноты еще на заре новой эры. Напомним: «...зло, свойственное нам, не представляет собой сущее зло, но есть лишь недостаток, отсутствие полноты свойственных нам благ», «зло представляет собой слабость и убывание Добра» (Дионисий Ареопагит, 2003: 379, 391). Соответственно, «добро» по Ареопагиту — это «полнота свойственных нам благ», воплощенная в «умственном Свете»: «Итак, умственным Светом называется превосходящее всякий свет Добро... все надмирные, около мира и в мире пребывающие умы от своей полноты просвещающее; все их мыслительные силы обновляющее... все умственное и разумное собирающее и сочетающее. Ибо так же, как неведение есть нечто разделяющее заблуждающихся, явление умственного Света есть нечто собирающее освещаемых... различные точки зрения... со- 
бирая к единому истинному, чистому, единовидному знанию...» (там же: 311).

В переводе на современный язык ареопагитовское «добро» сопоставимо с полнотой символических представлений о мире, включая их далеко еще не освоенные критической рефлексией формы. Соответственно, «зло» в ареопагитовской трактовке сопоставимо с их неполнотой. А чтобы убедиться, что сопоставления не произвольны, а оправданы реальным положением вещей, вспомним хотя бы о «бритве Оккама» («не умножай сущностей сверх необходимости»), в которой четко просматривается скороспелая претензия на исчерпывающее понимание природы «необходимости». Вспомним далее, что закономерным следствием оккамовской претензии явилось выросшее из просвещенческого «проекта модерна» научно-материалистическое мировоззрение, которое потому лишь и завладело так прочно умами, что все самое непонятное и загадочное в истории культуры «объяснило» путем его преждевременного списания в категорию «заблуждений», «суеверий» и «предрассудков». Наконец, вспомним, «что лишь благодаря Просвещению понятие предрассудка получает привычную для нас негативную окраску. Само по себе слово “предрассудок" (Vorurteil) означает пред-суждение (Urteil), вынесенное до окончательной проверки всех фактически определяющих моментов» (Гадамер, 1988: 322-323).

В свете такого взгляда на проблему смысловой полноты становится ясно, что знаменитое веберовское «расколдование мира», закрепившее в массовом сознании иллюзию его «объективного» восприятия, явилось на самом деле «заколдованием мира» - катастрофическим сужением общего мировоззренческого кругозора за счет отказа от научной рефлексии над списанными в «предрассудки» и в прочий «опиум для народа» смысловыми пластами символического языка. И в этом смысле намного большего доверия заслуживает здесь не М. Вебер с его «расколдованием», а. С. Пушкин, охарактеризовавший «прогрессистско-просвещенческую» философию энциклопедистов XVIII века как «принесшую миру так много хорошего, но несравненно больше дурного...» (Башилов, 1996: 286).

Все остальные формы смысловой неполноты (символического «зла») - это частные следствия из неполноты мировоззренческой, будь-то неполнота некой абстрактной, без обязанностей и ответственности и оттого разрушительной свободы (Горюнков, 2013: 156), или неполнота игнорирующего справедливость и становящегося поэтому бессовестным и подлым права (Горюнков, 2009: 114), или неполнота «невидимой руки» рыночной конкуренции, способной якобы все устроить наилучшим образом без государственного протекционизма (Менделеев, 2002: 389). А общая совокупность всех таких форм смысловой неполноты лишний раз подтверждает справедливость (и даже протонаучность) евангельской формулы «Весь мир лежит во зле» (1-е Ин., 5:19). 


\section{ДИАЛОГИЧЕСКИЙ АППАРАТ}

Исходные причины мировоззренческой неполноты коренятся в той особенности устройства символического языка, которое уместно назвать диалогическим аппаратом культуры (Горюнков, 2014: 164-198).

Бахтинская идея, согласно которой феномен культуры существует не иначе как в диалогическом режиме межсубъектных взаимодействий, давно уже воспринимается как хрестоматийная. Но мы очень мало поймем в конкретных исторических формах этого «режима», если по-прежнему не будем различать взаимодействий на уровнях практического и символического языков. А вот с учетом такого различения становится неизбежной постановка вопроса о наличии и сущности встроенного в символический язык и отвечающего за его историческую динамику диалогического аппарата. Доказательства существования такого аппарата хорошо просматриваются уже на древнейшей (мифологической) стадии развития культуры — в структуре явления, известного под названием дуальной организации родоплеменных обществ.

Суть дуальной организации заключается в разделении первобытных племен на две экзогамные ветви, объединенные символическими формами ритуальной вражды / взаимодействия. Первоначальное внимание в исследованиях этого феномена уделялось исключительно процессам заключения браков, организации племенной власти, играм и погребальным церемониям, возникновению классовых и имущественных различий. А расширение диапазона исследований в сторону изучения духовной, мировоззренческой составляющей феномена наметилось, по крайней мере, в СССР, лишь к середине $\mathrm{XX}$ века. Так, в капитальном труде А. М. Золотарева «Родовой строй и первобытная мифология», опубликованном в 1964 г., автор поставил перед собой задачу установить отражение дуальной организации в соответствующих космогонических (в частности, близнечных) мифах.

К сожалению, имеющийся в распоряжении специалистов материал по ранним формам культуры собирался в подавляющем большинстве случаев без учета дуальной специфики изучаемых обществ. Именно по этой причине он часто оказывается неполным и потому искажающим исходную картину. Тем не менее, даже он позволяет утверждать, что каждая фратрия располагала своим особенным мифологическим циклом, отличным от мифологического цикла другой фратрии (Золотарев, 1964: 117), и что имело место духовное различие между людьми разных фратрий, выражавшееся, в частности, в соотнесении образов близнецов-первопредков с фратриальными представлениями о положительном (добро) и отрицательном (зло) началах (Мифы народов мира, 1980: 389).

\section{ДИАЛОГИЧЕСКАЯ ДИССИММЕТРИЯ}

Поиски следов дуальной организации в раннеисторических представлениях о мире продолжили исследователи семиотической (московскотартуской) школы, занявшиеся сведением конкретных смысловых структур к двоичным символическим классификациям и изучению их отражения в древних культурах. Главное достижение на данном этапе исследований - фикса- 
ция асимметричности указанных классификаций (Иванов, 1978). Хотя правильнее, видимо, говорить об их диссимметрии, т.е. о соотношении их смысловой полноты и неполнотыл. В. И. Вернадский, например, считал, что «понятие асимметрия лучше оставить, так как оно, по-видимому, реально не существует...» (Вернадский, 1987: 184).

Неполная симметрия заключается в том, что исходный мифологический материал, имевший вид совокупности собственно мифов и исторических преданий (Топоров, 1982: 9-13), распределялся по фратриям в таком порядке: одна фратрия обладала полным набором мифов и исторических преданий, изображавших существующий мир как производный от предыдущего мира, а вторая - их неполным набором из одних исторических преданий, изображавших существующий мир как творимый «с нуля» (варианты: возникший из хаоса, самозародившийся). И в высшей степени показательно, что на сходное по сути соотношение обоих типов древних мировоззрений обратил внимание, хотя и безотносительно к теме дуальной организации, еще В. И. Вернадский в своих заметках по истории научных представлений о мире в культурах Запада и Востока (Вернадский, 1987: 313-314, гл. IX, 47).

Здесь нет возможности углубляться в теоретический материал по данной теме. Интересующиеся могут обратиться к его краткому обзору в энциклопедическом сборнике (Мифы ... , 1980: 174, 408, 572 и др.). Конкретные же примеры указанного распределения древних текстов по фратриям приведены в специальной работе (Горюнков, 2014: 164-198), и они показывают, что мифические близнецы-демиурги - патроны фратрий — потому только и являлись персонификаторами положительного и отрицательного начал, что именно с их личностями соотносились полнота и неполнота фратриальных представлений о мире. Так что вовсе не на пустом месте Ареопагит развивал свою трактовку понятий «добра» и «зла», а Бахтин выстраивал свою концепцию «диалога мировоззрений» - «последних позиций в мире в отношении высших ценностей» (Бахтин, 1997: 354).

\section{ИСТОРИЯ КАК ДИАЛОГ}

Одно то, что связи между фратриями различных племен всегда были сильнее межфратриальных связей внутри отдельного племени (Золотарев, 1964: 73), говорит в пользу универсальности принципов работы диалогического аппарата в истории культуры. Не удивительно, что с постепенным отмиранием дуальной организации носителями ее мировоззрений становились уже не фратриальные подразделения племен, а сами эти племена и целые народы. Соответственно, признаки прежних фратриальных различий превращались в признаки различения племен и народов, а диаметральнопротивоположные ценностные установки становились индикаторами культурно-исторических типов и цивилизационных общностей, принимая при этом предельно широкие формы «диалога культур». Проще же говоря, различные варианты диалога просматриваются в межплеменных и межэтнических разногласиях, в конфликтах между земледельцами и кочевниками, в религиозных противоречиях, в борьбе между классами, а затем и между поли- 
тико-экономическими моделями социальной организации - вплоть до межцивилизационного противостояния по ценностным критериям.

Последнее, между прочим, означает, что в истории культуры нет никаких «общечеловеческих ценностей», а есть лишь перманентный диалог двух противоположных, но не афишируемых в качестве таковых и принимаемых поэтому за «двойные стандарты», ценностных позиций. Причем диалог этот не исключает и искусственных влияний на данные позиции, вплоть до их радикальных перекодировок, способных оборачиваться военными конфликтами.

\section{«БОЛЬШОЙ»И «МАЛЬЙџ ОПЫТЫ}

Конфликтность отношений между диалогическими позициями четко прослеживается в бахтинской трактовке диалога как противостояния полноты «большого опыта» неполноте «малого»: «В символах официальной культуры лишь малый опыт специфической части человечества (притом данного момента, заинтересованного в стабильности его). Для этих малых моделей, созданных на основе малого и частного опыта, характерна специфическая прагматичность, утилитарность. Они служат схемой для практически заинтересованного действия человека, в них, действительно, практика определяет познание. Поэтому в них нарочитое утаивание, ложь, спасительные иллюзии всякого рода, простота и механичность схемы, односмысленность и односторонность оценки, одноплановость и логичность (прямолинейная логичность). Они менее всего заинтересованы в истине всеобъемлющего целого (эта истина целого непрактична и бескорыстна, она безразлична к временным судьбам частного). Большой опыт заинтересован в смене больших эпох (большом становлении) и в неподвижности вечности, малый же опыт - в изменениях в пределах малой эпохи (в малом становлении) и во временной, относительной стабильности. Малый опыт построен на нарочитом забвении и на нарочитой неполноте. В большом опыте мир не совпадает с самим собою (не есть то, что он есть), не закрыт и не завершен. <..> Малый опыт, практически осмысленный и потребляющий, стремится все омертвить и овеществить, большой опыт - все оживить (во всем увидеть незавершенность и свободу, чудо и откровение). В малом опыте - один познающий (все остальное объект познания), один свободный субъект (все остальное - мертвые вещи), один живой и незакрытый (все остальное - мертво и закрыто), один говорит (все остальное безответно молчит). В большом опыте все живо, все говорит, этот опыт глубоко и существенно диалогичен» (Бахтин, 1992: 158; курсив наш. - C. Г.).

Но очевидные преимущества большого опыта перед малым вовсе не означают массового стремления к овладению именно им, - ситуация, скорее, обратная. Дело в том, что причастность малому опыту — это всегда строгое соблюдение общепринятых «правил игры» (выражаемое в присущих текущему моменту штампах символического языка), в то время как причастность большому - это вынужденный вызов указанным правилам. Вызов же связан обычно с теми или иными издержками, от несогласия с господствующим дискурсом до полного выпадения из него. Чему способствует и разность 
ментальных установок: носители малого опыта - это люди, исходящие из того, что все, нужное им, они и так знают; носители же большого опыта это жертвы «сократовского комплекса»: чем больше они знают, тем яснее понимают, как мало они знают.

Ситуация усугубляется и тем, что с древности присущее дуальной организации статусное неравенство фратрий (чисто условное по Золотареву) оказывается первоисточником всех позднейших, связанных с завышенной самооценкой, претензий на разного рода коллективное превосходство, от «богоизбранности» до «расовой (национальной) исключительности» и прочих им подобных заявок на «групповую элитарность» (Горюнков, 2014: 182185). А все такие претензии оборачиваются обычно диалогическим «сбоем» - монологизмом малого опыта с его самоприсвоенным правом нести в массы «букву единственно верных истин» (о боге ли, о коммунизме, о демократии и т. п.).

\section{ПУЛЬСИРУЮЩАЯ КУЛЬТУРА}

Диалог двух видов опыта - это всегда противостояние двух различных предпосылочных установок: той традициональной (уходящей в глубины истории культуры), что далека от завершенности и полна смутных догадок о невообразимой сложности и чудесной загадочности мироустройства, и той «прогрессистской» (упрощенной, логически завершенной, возведенной в статус «символа официальной культуры), что преисполнена самодовольной веры в собственную непогрешимую «научность» и «объективность». При этом в каждой из диалогических позиций отношение к своим предпосылочным установкам проявляется по-разному. Например, позиция «полноты предпосылок» отличается устойчивым консерватизмом - либо в ее мифорелигиозной форме, либо в попытках эту форму научно отрефлексировать, но ни в коем случае не упразднить. А упрощенная «прогрессистская» позиция отмечена столь же устойчивой нацеленностью на достижение «беспредпосылочного» («наивного» по Х.-Г. Гадамеру) знания о мире.

Вторая позиция - это состояние символического языка, имеющего тенденцию «скатываться» к практическому. А поскольку в повседневной бытовой коммуникации символический и практический языки различаются, как правило, очень слабо, то и диалог между позициями оборачивается бессознательной смысловой редукцией символического языка - сведением его полисемантичности к большей или меньшей степени однозначности.

В смысловой редукции символического языка выражается стремление к обретению «единственно правильных» стандартов мышления, говорения и поведения. Людям всегда хочется сделать языковую среду более понятной для себя путем сведения ее многозначности к четким дефинициям. На практике это выражается в том, что по мере накопления критических рефлексий над смысловой структурой символического языка общепринятые представления о мире перестают убеждать, и возникает потребность в их пересмотре. А в ходе пересмотра и складываются очередные, претендующие на «окончательную истинность» формы мировосприятия, сводящие полисемантизм 
символического языка к более или менее терпимому минимуму: мифорелигиозные картины мира, философские учения, концепции национального суверенитета и социального порядка, научные парадигмы.

В истории культуры все эти формы служат оазисами семантической стабильности: в них подытоживается накопленный предыдущими поколениями опыт, обретается личная и коллективная идентичность, формируется поле так называемого «здравого смысла» (стиля мышления, находящегося в бессознательной зависимости от текущих семантических конструкций и приравнивающего поэтому видимое к сущему), упрощается коммуникация, создаются условия для отдыха от «бремени культуры». Но такое - расслабленное - существование внутри оазисов неизбежно снижает качество мыследеятельности: усиливает зависимость сознания от слов (Горюнков, 2013: 149). Ведь смыслы не только «делают нас активными, психически здоровыми», но и «могут нас угнетать, подавлять, догматизировать. И чтобы этого не было, смыслы должны все время обновляться, в соответствии с меняющейся ситуацией» (Налимов, 2011: 281).

Не следует лишь путать такое обновление смыслов с «высасыванием из пальца» их искусственных форм (типа ЛГБТ). Перманентная смысловая редукция - это причинно-обусловленная форма выражения исторической динамики культуры - ее пульсации: сначала - затухание активной мыследеятельности вследствие шаблонизации и догматизации ее языковых форм и накопления обнажающихся противоречий, затем - ее активизация как результат снятия противоречий. Снятие же осуществляется средствами иносказательности, т. е. перебором вариантов описания оазисов, выводящим на новые противоречия.

При этом затухающая фаза пульсации может восприниматься поразному: и как «стагнация», и как «верность традициям». И так же поразному может восприниматься ее активная фаза. Например, она может трактоваться в духе китайской поговорки: «Чтоб тебе жить в эпоху перемен!» А может принимать форму манифеста, столь ярко заявленного словами известной песни В. Р. Цоя: «Перемен! Мы ждем перемен!».

\section{КРИЗИС ПОНИМАНИЯ}

Вот пример функционирования модели пульсирующей культуры внутри того оазиса семантической стабильности, который известен под названием «эволюционно-исторической парадигмы мышления». Как показано во Введении, поиски границы между природой и культурой, ведущиеся в рамках данной парадигмы, оборачиваются противоречиями, а затем их временными снятиями, высвечивающими новые противоречия. В частности, выше было показано, как противоречие между разными взглядами на границу между языками природы и культуры снимается обнаружением в «естественном языке» двух его различных составляющих. Но при этом высвечивается новое противоречие: в каждой из составляющих разным оказывается само понимание. В практическом языке понимание - это соответствие его составляющих тем или иным аспектам внеязыковой реальности. В замкнутом же на себя 
символическом языке это узнавание сходных смысловых структур, т. е. иллюзия понимания, а, значит, научная проблема.

Проблема эта осознается даже далекими от науки людьми: «Доступность, понятность слов еще не обозначает “понятность" мысли...» (Свиридов, 2002: 129). Соответственно, зафиксирована она и в специальной литературе: «...XX век оставил нам в наследство... глобальную проблему — неосознанность происходящего, иначе говоря — кризис понимания. ... это самая главная из всех глобальных проблем - проблема № 1» (Ильинский, 2016: 21). Ведь «сплошь и рядом мы знаем слова и названия явлений, событий, процессов, но не их содержание, не глубинный смысл, т. е. сущность» (там же: 23; полужирный шрифт источника. - C. Г.).

\section{СВЯЗЬ РЕАЛЬНОСТЕЙ}

«Сегодня, - пишет И. М. Ильинский, — в кризисе понимания находит свое выражение системный кризис бытия человечества вообще» (там же: 26). Объясняемый по сложившейся инерции экономическими, геополитическими, межэтническими и прочими тому подобными причинами, он является на самом деле кризисом в осмыслении предпосылочных основ культуры. Причина же последнего коренится в массовом научном конформизме - в укоренившейся за последнее столетие привычке решать главные методологические вопросы не иначе как с оглядкой на тезис о примате бытия над мышлением.

Данный тезис ничем до сих пор не подкреплен и не оправдан (Горюнков, 2015: Электронный ресурс); тем не менее, он почему-то продолжает восприниматься массовым научным сознанием не как исторически обусловленный ментальный конструкт, а как объективная данность. И в таком своем восприятии он не нуждается ни в собственном обосновании, ни в окончательном признании замкнутости символического языка на себя, ни, тем более, в ответе на вопрос: каким образом этот замкнутый на себя язык соотносится с внеязыковой реальностью?

Тем не менее, отвечать на этот вопрос рано или поздно все равно придется. А ответ на него предвидится только в такой форме: смысловая реальность символического языка соотносится с внеязыковой реальностью не отдельными своими составляющуими, как в практическом языке, а всей своей смысловой полнотой и изелостностью.

\section{ПРОБЛЕМА «КРУГА»}

Неизбежность именно такого ответа предопределена необходимостью решения проблемы «круга понимания» (Хайдеггер, 2006: 152), известного также под названиями «логического», «порочного» и прочих «кругов».

Проблема «круга» - это прямое следствие из ее причины: замкнутости символического языка на себя. Но если, повторимся, причина «круга» современной наукой игнорируется, то с самим выпирающим из всех щелей «кругом» поневоле приходится считаться. Поэтому ситуация с ним неоднозначная: хотя «круг» и признается проблемой, но - второстепенного порядка. Это видно из того, что он до сих пор воспринимается как следствие несовер- 
шенства доказательной процедуры: считается, что если данную процедуру усовершенствовать, то и «круг» исчезнет (Горюнков, 2018: 127-129).

Тупик усугубляется модной сегодня постмодернистской трактовкой истории культуры, в свете которой любые языковые проблемы, включая и проблему «круга», выглядят не более чем производными от «языковых игр» симулякрами (Ж. Бодрийяр и др.) Ведь с постмодернистской точки зрения «мир есть не что иное как текст, однако лишенный авторского замысла и оставляющий за читателем неограниченную свободу его интерпретации. Соответственно, если в рамках культуры модерна языковой знак обозначает и указывает на некий объект, то в рамках постмодерна знак означает только сам себя» (Строев, 2013: Электронный ресурс). А значит, «и обмен словами представляет собой не более, чем игру знаками, определенными лишь по отношению к другим знакам, и совершенно не имеющую отношения к какому бы то ни было знанию о трансцендентной по отношению к языку реальности» (там же).

\section{ВХОЖДЕНИЕ В «КРУГ»}

Тем не менее, решение проблемы «круга» вполне возможно, - при условии, что ставится задача не выхода из «круга», а вхождения в него. Теоретически именно так предлагал решать проблему еще М. Хайдеггер (Хайдеггер, 2006: 153). А первая практическая попытка «входа в круг» была предпринята около тридцати лет тому назад автором данной статьи (Горюнков, 1991: 92; 1993: 16). Основывалась она на принципе «черного ящика»понятия кибернетики, введенного в научный обиход с целью справиться с трудностями изучения сложных систем (Словарь по кибернетике, 1979: 592).

Представление системы в виде «черного ящика», состоящего из «входа» и «выхода», означает, что при настоящем уровне наших знаний мы не можем проникнуть внутрь данной системы и разобраться, каким образом «входные» условия преобразуются в ситуацию на «выходе» (там же). Однако предположив, что ситуация на «выходе» (в нашем случае - смысловая организация древнейшей фазы символического языка) предопределена «входными» условиями (в нашем случае - непонятными нам причинами возникновения этого языка), мы можем по результатам анализа ситуации «на выходе» судить и о сущности самих «входных» условий.

Под анализом «ситуации на выходе» подразумевается анализ той загадочной упорядоченности древнейшей фазы символического языка, которая проявляет себя в так называемых повторяемостях мифологических мотивов. Дело в том, что в ситуации «круга» эти повторяемости должны интерпретироваться не исторически (как следствие родства по происхождению, или как результат сходных условий общественного развития, или как продукт взаимовлияний и заимствований), а типологически: как проявление некоего инварианта, сохраняющегося при любых преобразованиях.

Имеется в виду то соотношение постоянных и переменных величин в фольклорных текстах, которое было обнаружено В.Я. Проппом применительно к волшебным сказкам и изучение которого он предполагал (но по ря- 
ду причин не сумел) продолжить применительно к мифам (Пропп, 1928: 7). Между тем, по предварительным данным, аналогичное соотношение постоянных и переменных величин прослеживается и на мифологическом материале (Горюнков, 2014: 54-67), — чем создается реальная перспектива прочтения инвариантного содержания символического языка во всей его смысловой полноте и целостности (там же: 68-79).

Самые первые шаги в направлении такого прочтения показали, что пропповская структура волшебных сказок, проанализированная на «более абстрактном уровне больших синтагматических единств» (Мелетинский, 1998: 440-460), целиком совпадает с последовательностью фазовых изменений мифологической модели мира (Горюнков, 2014: 213-214). Последняя же, как показано в целом ряде статей автора начиная с публикации 1991 г., представляет собой упрощенную форму выражения структуры самовоспроизводственного или матричного принципа (Горюнков, 2014: 74-79). Т. е. древнейшая форма символического языка обнаруживает свойства метаязыка с многообещающим смысловым наполнением (там же).

\section{ЗАКЛЮЧЕНИЕ}

Вхождение в «круг» - это сигнал, оповещающий, что навязанный нам просвещенческим «проектом модерна» взгляд на себя как на творцов и хозяев собственной культуры окончательно себя изжил. В свете эмпирических данных мы, скорее, похожи на запрограммированных культурой и «играющих в нее» детей. Но играющих не по собственному произволу и хотению, в чем до сих пор убеждено подавляющее большинство представителей научного сообщества, а по заданным самой культурой (ее структурой, динамикой и функциями) правилам. (Именно поэтому, кстати, ничто и никогда не совершается в истории в точности так, как прогнозируется обычно политтехнологами). Надежды же на духовное повзросление приходится в этой ситуации связывать исключительно с дальнейшим изучением символического языка, причем не только его «непроявленной семантики», его «нераспакованных смыслов» (термины В. В. Налимова), но также его ловушек и издержек (Горюнков, 2015а: 44; он же, 2018а: 1-2).

Начинаться такое изучение должно, разумеется, с обновления предпосылочной базы. Что, собственно, уже и происходит: «Сегодня задачей любого мыслящего человека является демистификация моделей и анализ их истоков. Мы должны пройти к самым основаниям тех утверждений, на которых они базируются и к которым мы привыкаем из-за идеологической обработки в школе и в средствах массовой информации» (Кара-Мурза, 1982: 118; выделено нами. - C. Г.). А опора на обновленные предпосылки помогает окончательно понять, что «все неудачи в попытке построить содержательную модель сознания кроются в страхе прослыть идеалистом. Нельзя сказать чтолибо серьезное о сознании, не постулировав изначальное сущзествование непроявленной семантики» (Налимов, 2011: 299; курсив источника. - С. Г.).

В общенаучном контексте речь идет, как видим, о явлении, которое по инерции, восходящей к научному наследию В. И. Вернадского, принято 
называть сменой мировоззренческой парадигмы. Напомним, что говорил об этой смене сам Вернадский: 1) «Мы подходим к очень ответственному времени, к коренному изменению нашего научного мировоззрения» (Вернадский, 1931: 417); 2) «То, что казалось логически и научно неизбежным, в конце концов оказалось иллюзией, и явление предстает нам в таких формах, которые никем не ожидались» (Вернадский, 1967: 236). Что касается нашей конкретной темы, то первостепенного внимания заслуживает следующая догадка Вернадского: «...ход развития человеческой мысли вполне аналогичен естественным процессам, т. е. совершается не по законам человеческой логики, а по своим неведомым и непредвидимым нами путям» (Вернадский, 1988: 221). Свое современное продолжение и развитие эта догадка находит, как известно, в исследованиях, посвященных проблеме изоморфизма между генетическим и ментально-языковым кодами (Гамкрелидзе, 1988: 5; см. также: Горюнков, 2014: 212).

И в завершение темы - несколько высказываний прогностического характера о ситуации, сложившейся в области исследования древнейшей фазы символического языка.

У В. Н. Топорова читаем: «...в высшей степени характерно, что современная наука приходит к исключительно высокой оценке операционной ценности и познавательной силы первобытного знания именно в самые последние годы» (Топоров, 1982: 37). О том же - у Х.-Г. Гадамера: «Если откроешь историко-научное собрание де Врие "История исследования мифологии", то получишь то же впечатление, как и от “Кризиса историзма", — оно сказалось на новом оживлении интереса к мифологии. <...> Достоин особого внимания тот факт, как решительно признаются Вальтер Ф. Отто и Карл Кереньи первооткрывателями нового исследовательского направления, воспринимающего мифы всерьез» (Гадамер, 1988: 583). У В. В. Налимова: «Странно, но сейчас приходится задумываться над концепциями далекого прошлого» (Налимов, 1978: 69). И о том же, но в более отвлеченной, теоретизированной форме, у М. Хайдеггера: «...онтологические предпосылки историографического познания принципиально превосходят идею строгости самых точных наук. Математика не строже историографии, а просто более узка в отношении круга релевантных для нее экзистенциальных оснований» (Хайдеггер, 2006: 153).

\section{СПИСОК ЛИТЕРАТУРЫ}

Абаев, В. И. (1976) О термине «естественный язык» // Вопросы языкознания. № 4. С. 77-80.

Аверинцев, С. С. (2001) София-Логос : словарь. 2-е изд., испр. Киев : Дух і Літера. 460 с.

Бахтин, М. М. (1986) Эстетика словесного творчества. 2-е изд. М. : Искусство. 445 с.

Бахтин, М. М. (1992) Из черновых тетрадей // Литературная учеба : литературно-художественный журнал. № 5-6 (сентябрь — декабрь). С. 153156. 
Бахтин, М. М. (1997) Собр. соч. : в 7 т. М. : Русские словари ; Языки славянской культуры. Т. 5.731 с.

Башилов, Б. (1996) Пушкин и масонство (главы из книги) // А. С. Пушкин: путь к православию. М. : Отчий дом. 335 с. С. 270-299.

Бор, Н. (1961) Атомная физика и человеческое познание. М. : Изд-во иностранной литературы. $151 \mathrm{c}$.

Вернадский, В. И. (1931) Изучение явлений жизни и новая физика // Известия Академии наук СССР. Серия 7. Отделение математических и естественных наук. № 3. С. 403-437.

Вернадский, В. И. (1967) Биосфера. М. : Мысль. 376 с.

Вернадский, В. И. (1987) Химическое строение биосферы Земли и ее окружения. 2-е изд. М. : Наука. 340 с.

Вернадский, В. И. (1988) Философские мысли натуралиста. М. : Наука. $520 \mathrm{c}$.

Гадамер, Х.-Г. (1988) Истина и метод: Основы философской герменевтики. М. : Прогресс. 704 с.

Гадамер, Х.-Г. (1991) Актуальность прекрасного. М. : Искусство. 367, [1] c.

Гамкрелидзе, Т. В. (1988) Р. О. Якобсон и проблема изоморфизма между генетическим кодом и семиотическими системами // Вопросы языкознания. № 3. С. 5-8.

Горюнков, С. В. (1991) О соотношении мифологии и онтологии (в свете идей В. И. Вернадского) // Ноосфера и художественное творчество : сб. ст. / отв. ред. Вяч. Вс. Иванов. М. : Наука. 280 с. С. 88-100.

Горюнков, С. В. (1993) О жизни, смерти и бессмертии как о метаязыковом содержании мифов // Жизнь. Смерть. Бессмертие : мат. науч. конф., проведенной в декабре 1993 г. в Санкт-Петербурге Государственным музеем истории религии. СПб. : Образование. 128 с. С. 16-18.

Горюнков, С. В. (2009) Приведет ли нас право к правде? // Горюнков С. В. Глобальный кризис как шанс поумнеть. СПб. : Изд. дом «Нравственный мир». 120 с. С. 114-118.

Горюнков, С. В. (2013) В рабстве у слов // Нева. № 8. С. 149-167.

Горюнков, С. В. (2014) Мета-коды культуры. СПб. : ООО «Контраст». $304 \mathrm{c}$.

Горюнков, С. В. (2015) Зомбирование по-академически (курс лекций). Лекция I: Научная мантра [Электронный ресурс] // Институт нравственности. 15 апреля. URL: http://in.ast.social/420-zombirovanie-po-akademicheski-nauchnaya-mantra.html [архивировано в WaybackMachine] (дата обращения: 20.11. 2018).

Горюнков, С. В. (2015а) Между верой и знанием: ловушка псевдовыбора // Тринадцатый Славянский научный собор «Урал. Православие. Культура». Кирилло-Мефодиевская традиция в культуре России: история в современности : мат. Всероссийской научно-практической конференции / сост. И. Н. Морозова, С. С. Бредихин ; Челяб. гос. акад. культуры и искусства. Челябинск. 315 с. С. $44-53$. 
Горюнков, С. В. (2016) К вопросу о переоснащении теоретикометодологического аппарата исторической науки // Знание. Понимание. Умение. № 3. С. 193-207. DOI: 10.17805/zpu.2016.3.15

Горюнков, С. В. (2017) О проблемах изучения внутреннего мира личности в свете кризиса методологической мысли // Ученые записки СанктПетербургского государственного института психологии и социальной работы. № 2 (28). С. 15-21.

Горюнков, С. В. (2018) О научной мифологии и о «круге в доказательстве» // Homo eurasicus в системах экологических и социальных связей : коллективная монография по материалам VIII Международной научнопрактической конференции 24 октября 2017 г. СПб. : L-Print. 139 с. C. 125130.

Горюнков, С. В. (2018а) Что такое идеология? // Литературный СанктПетербург : газета Санкт-Петербургского отделения Союза писателей России. № 4 (31). Июль. С. 1-2. URL: http://litgazeta.dompisatel.ru/archives/1398 [архивировано в WaybackMachine] (дата обращения: 10.12.2018).

Даль, В. И. (1996) Толковый словарь живого великорусского языка : в 4 т. СПб. : ООО «Диамант». Т. 2. 784 с.

Дионисий Ареопагит. (2003) Сочинения. Толкования Максима Исповедника. СПб. : Алетейя. 864 с.

Зелинский, С. А. (2008) Манипуляции массами и психоанализ. Манипулирование массовыми психическими процессами посредством психоаналитических методик. СПб. : Издательско-торговый дом «СКИФИЯ». 248 c.

Золотарев, А. М. (1964) Родовой строй и первобытная мифология. М. : Наука. 328 с.

Иванов, Вяч. Вс. (1978) Чет и нечет. Асимметрия мозга и знаковых систем. М. : Советское радио. 184 с.

Иванов, Вяч. Вс. (2004) Наука о человеке: Введение в современную антропологию : курс лекций. М. : РГГУ. 195 с.

Ильинский, И. М. (2016) О «правильном образовании» для России XXI века // Знание. Понимание. Умение. № 3. С. 5-31. DOI: 10.17805/zpu.2016.3.1

Кабыш, И. А. (2007) Между Болдино и компьютером // Литературная газета. № 50 (6150). 12-18 декабря. C. 13. URL: http://www.lgz.ru/article/N50-6150---2007-12-12-/Mezhdu-Boldino-i-kompyyuterom2547/ [архивировано в WaybackMachine] (дата обращения: 20.11.2018).

Кара-Мурза, С. Г. (2002) Идеология и мать ее наука. М. : Эксмо. 256 с.

Кармин, А. С. (2011) Культурология : учебник. 6-е изд. СПб. : Лань ; Планета музыки. 928 с.

Кассирер, Э. (2002) Философия символических форм : в 3 т. М. ; СПб. : Университетская книга. Т. 1: Язык. 272 с.

Колесов, В. В. (1998) Русская речь. Вчера. Сегодня. Завтра. СПб. : Юна. $248 \mathrm{c}$.

Леви-Стросс, К. (1978) Миф, ритуал и генетика // Природа. № 1. С. 90 106. 
Леонтьев, Д. А. (2007) Психология смысла : природа, строение и динамика смысловой реальности. 3-е изд., доп. М. : Смысл. 511 с.

Луков, В. А., Луков, Вл. А. (2006) Теория тезаурусного подхода // Гуманитарное знание: тенденции развития в XXI веке / под общей ред. В. А. Лукова. М. : Изд-во Нац. ин-та бизнеса. 680 с. С. 557-565.

Луков, В. А., Луков, Вл. А. (2008) Тезаурусы: субъектная организация гуманитарного знания. М. : Изд-во Нац. ин-та бизнеса. 784 с.

Луков, Вл. А. (2008) Субъектная культурология [Электронный ресурс] // Электронный журнал «Знание. Понимание. Умение». № 4. URL: http://www.zpu-journal.ru/e-zpu/2008/4/Lukov_culturology/ [архивировано в WaybackMachine] (дата обращения: 20.11.2018).

Мелетинский, Е. М. (1998) Структурно-типологическое изучение сказки // Пропп В. Я. Морфология <волшебной> сказки. Исторические корни волшебной сказки. М. : Лабиринт. 512 с. С. 437-466.

Менделеев, Д. И. (2002) К познанию России. М. : Айрис-пресс. 576 с.

Мировой общественный форум «Диалог цивилизаций» (2013) : манифест [Электронный ресурс] // CCCP 2.0. URL: http://www.ussr-2.ru/ index.php/sssr-2-0/dialog-tsivilizatsij/1637-mirovoj-obshchestvennyj-forum-dialog -tsivilizatsij-2013?showall=\&start=3 [архивировано в WaybackMachine] (дата обращения: 20.11.2018).

Мифы народов мира (1980) : в 2 т. / гл. ред. С. А. Токарев. М. : Советская энциклопедия. Т. І: А-К. 672 с.

Налимов, В. В. (1978) Непрерывность против дискретности в языке и мышлении. Тбилиси : Изд-во Тбилисского ун-та. 84 с.

Налимов, В. В. (1989) Возможно ли учение о человеке в единой теории знания? // Человек в системе наук / отв. ред. И. Т. Фролов. М. : Наука. 504 с. C. 82-91.

Налимов, В. В. (2011) Спонтанность сознания. Вероятностная теория смыслов и смысловая архитектоника личности. М. : Академический проект ; Парадигма. 399 с.

Памятники литературы Древней Руси. Вторая половина XVI века (1986) / вступ. статья Д. С. Лихачёва ; сост. и общ. ред. Л. А. Дмитриева и Д. С. Лихачёва. М. : Художественная литература. 640, [4] с.

Полани, М. (1985) Личностное знание. На пути к посткритической философии. М. : Прогресс. 344 с.

Преподобный Иосиф Волоцкий. (1993) Просветитель. М. : Изд. СпасоПреображенского Валаамского монастыря. 382 с.

Принципы описания языков мира. (1976) М. : Наука. 343 с.

Пропп, В. Я. (1928) Морфология сказки. Л. : Academia. 152 с.

Рикер, П. (1995) Конфликт интерпретаций. Очерки о герменевтике. М. : Медиум. 415 с.

Свиридов, Г. В. (2002) Музыка как судьба. М. : Молодая гвардия. 798 с.

Славянские древности (1999) : этнолингвистический словарь : в 5 т. / под общ. ред. Н. И. Толстого. М. : Международные отношения. Т. 2: Д-К. 697, [1] c. 
Словарь по кибернетике (1979) / под ред. академика В. М. Глушкова. Киев : Главная редакция Украинской советской энциклопедии. $623 \mathrm{c.}$

Смирнова-Россет, А. О. (2003) Записки. М. : Захаров. 528 с.

Страницы автобиографии В. И. Вернадского (1981) / В. И. Вернадский ; сост. Н. В. Филиппова. М. : Наука. 349 с.

Строев, С. А. (2013) Постиндустриальный симулякр: добро пожаловать в ролевую игру [Электронный ресурс] // Портал «Русская народная линия: информационно-аналитическая служба». 17 декабря. URL: http://ruskline.ru/analitika/2013/12/17/postindustrialnyj_simulyakr_dobro_pozhalovat_v_role vuyu_igru/ [архивировано в WaybackMachine] (дата обращения: 20.11.2018).

Топоров, В. Н. (1982) Первобытные представления о мире (общий взгляд) // Очерки истории естественно-научных знаний в древности / отв. ред. А. Н. Шамин. М. : Наука. 278 с. С. 8-40.

Трунов, Д. Г. (2000) Иносказательная природа самоотчуждения как социокультурного феномена : дис. ... канд. филос. наук. Пермь. 139 с.

Фрейд, 3. (2007) Неудовлетворенность культурой // Фрейд 3. Собр. соч. : в 10 т. М. : ООО «Фирма СТД». Т. 9.607 с. С. 191-270.

Хайдеггер, М. (1993) Время и бытие : статьи и выступления. М. : Республика. 447 с.

Хайдеггер, М. (2006) Бытие и время. СПб. : Наука. 452 с.

Черниговская, Т. В. (2008) Язык и сознание: что делает нас людьми? (Лекция, прочитанная 20 ноября 2008 г. в клубе - литературном кафе Bilingua в рамках проекта «Публичные лекции Полит.ру») [Электронный ресурс] // Полит.ру. 24 декабря. URL: https://polit.ru/article/2008/12/24/langmind/ [архивировано в WaybackMachine] (дата обращения: 20.11.2018).

Элиаде, М. (2000) Аспекты мифа. М. : Академический проект. 222 с.

Энгельс, Ф. (1982) Диалектика природы. М. : Политиздат, XVI, 359 с.

Дата поступления: 27.11.2018 2.

\section{REFERENCES}

Abaev, V. I. (1976) O termine «estestvennyi iazyk» [The term "natural language”]. Voprosy iazykoznaniia, no. 4, pp. 77-80. (In Russ.).

Averintsev, S. S. (2001) Sofiia-Logos [Sophia-Logos] : A dictionary. 2nd edn., revised. Kiev : Dukh i Litera Publ. 460 p. (In Russ.).

Bakhtin, M. M. (1986) Estetika slovesnogo tvorchestva [Aesthetics of verbal art]. 2nd edn. Moscow : Iskusstvo Publ. 445 p. (In Russ.).

Bakhtin, M. M. (1992) Iz chernovykh tetradei [From draft notes]. Literaturnaia ucheba, no. 5-6 (September - December), pp. 153-156. (In Russ.).

Bakhtin, M. M. (1997) Sobranie sochinenii [Collected Works] : in 7 vols. Moscow : Russkie slovari Publ. ; Iazyki slavianskoi kul'tury Publ. Vol. 5. 731 p. (In Russ.).

Bashilov, B. (1996) Pushkin i masonstvo (glavy iz knigi) [Pushkin and Freemasonry (chapters from the book)]. In: A. S. Pushkin: put' k pravoslaviiu 
[A. S. Pushkin: The path to Orthodoxy]. Moscow : Otchii dom Publ. 335 p. Pp. 270-299. (In Russ.).

Bohr, N. (1961) Atomnaia fizika i chelovecheskoe poznanie [Atomic physics and human knowledge]. Moscow : Publ. House of Foreign Literature. 151 p. (In Russ.).

Vernadsky, V. I. (1931) Izuchenie iavlenii zhizni i novaia fizika [A study of the phenomena of life and new physics]. Izvestiia Akademii nauk SSSR. Seriia 7. Otdelenie matematicheskikh i estestvennykh nauk, no. 3, pp. 403-437. (In Russ.).

Vernadsky, V. I. (1967) Biosfera [Biosphere]. Moscow : Mysl’ Publ. 376 p. (In Russ.).

Vernadsky, V. I. (1987) Khimicheskoe stroenie biosfery Zemli i ee okruzheniia [Chemical composition of Earth's biosphere and its surroundings]. 2nd edn. Moscow : Nauka Publ. 340 p. (In Russ.).

Vernadsky, V. I. (1988) Filosofskie mysli [Philosophical thoughts of a naturalist]. Moscow : Nauka Publ. 520 p. (In Russ.).

Gadamer, H.-G. (1988) Istina i metod: Osnovy filosofskoi germenevtiki [Truth and method: Basics of philosophical hermeneutics]. Moscow : Progress Publ. 704 p. (In Russ.).

Gadamer, H.-G. (1991) Aktual'nost' prekrasnogo [Relevance of the beautiful]. Moscow : Iskusstvo Publ. 367, [1] p. (In Russ.).

Gamkrelidze, T. V. (1988) R. O. Iakobson i problema izomorfizma mezhdu geneticheskim kodom i semioticheskimi sistemami [R. O. Jacobson and the problem of isomorphism between the genetic code and semiotic systems]. Voprosy iazykoznaniia, no. 3, pp. 5-8. (In Russ.).

Goryunkov, S. V. (1991) O sootnoshenii mifologii i ontologii (v svete idei V. I. Vernadskogo) [Correlation between mythology and ontology (In the light of V. I. Vernadsky's ideas]. In: Noosfera i khudozhestvennoe tvorchestvo [Noosphere and artistic creativity] : collected papers. Moscow : Nauka Publ. 280 p. Pp. 88100. (In Russ.).

Goryunkov, S. V. (1993) O zhizni, smerti i bessmertii kak o metaiazykovom soderzhanii mifov [Life, death and immortality as a metalinguistic content of myths]. In: Zhizn'. Smert'. Bessmertie [Life, death and immortality] : Proceedings of the conference convened in December 1993 by St. Petersburg State Museum of the History of Religion. St. Petersburg : Obrazovanie Publ. 128 p. Pp. 16-18. (In Russ.).

Goryunkov, S. V. (2009) Privedet li nas pravo k pravde? [Will law lead us to the truth?]. In: Goryunkov, S. V. Global'nyi krizis kak shans poumnet' [Global crisis as a chance to become smarter]. St. Petersburg : Publ. House "Nravstvennyi mir”. 120 p. Pp. 114-118. (In Russ.).

Goryunkov, S. V. (2013) V rabstve u slov [Being slaves of words]. Neva, no. 8, pp. 149-167. (In Russ.).

Goryunkov, S. V. (2014) Meta-kody kul'tury [The Meta-codes of culture]. St. Petersburg : Kontrast LLC. 304 p. (In Russ.).

Goryunkov, S. V. (2015a) Zombirovanie po-akademicheski (kurs lektsii). Lektsiia I: Nauchnaia mantra [Academic zombification (A course of lectures). Lec- 
ture I: Scientific mantra]. Institut nravstvennosti, April 15. [online] Available at: http://in.ast.social/420-zombirovanie-po-akademicheski-nauchnaya-mantra.html [archived in WaybackMachine] (accessed 20.11.2018). (In Russ.).

Goryunkov, S. V. (2015b) Mezhdu veroi i znaniem: lovushka psevdovybora [Between faith and knowledge: A trap of pseudo-choice]. In: Trinadtsatyi Slavianskii nauchnyi sobor «Ural. Pravoslavie. Kul'tura» : Kirillo-Mefodievskaia traditsiia v kul'ture Rossii: istoriia v sovremennosti [The thirteenth Slavic research forum "Ural. Orthodoxy. Culture". The Cyril and Methodius tradition in Russian culture: history in modern times] : Proceedings of the All-Russian research-topractice conference / comp. by I. N. Morozova, S. S. Bredikhin ; Chelyabinsk State Academy of Culture and Art. Chelyabinsk. 315 p. P. 44-53. (In Russ.).

Goryunkov, S. V. (2016) K voprosu o pereosnashchenii teoretikometodologicheskogo apparata istoricheskoi nauki [Refurbishing the methodology of historical research]. Znanie. Ponimanie. Umenie, no. 3, pp. 193-207. (In Russ.). DOI: $10.17805 / \mathrm{zpu} .2016 .3 .15$

Goryunkov, S. V. (2017) O problemakh izucheniia vnutrennego mira lichnosti v svete krizisa metodologicheskoi mysli [On the problems of studying the inner world of a person in the light of the crisis of methodological thought]. Uchenye zapiski Sankt-Peterburgskogo gosudarstvennogo instituta psikhologii i sotsial'noi raboty, no. 2 (28), pp. 15-21. (In Russ.).

Goryunkov, S. V. (2018a) O nauchnoi mifologii i o «kruge v dokazatel'stve» [On scientific mythology and the "circle in proving"]. In: Homo eurasicus $v$ sistemakh ekologicheskikh i sotsial'nykh sviazei [Homo eurasicus in the systems of ecological and social connections] : A multi-authored monograph containing the proceedings of the 8th International research-to-practice conference, October 24, 2017. St. Petersburg : L-Print Publ. 139 p. Pp. 125-130. (In Russ.).

Goryunkov, S. V. (2018b) Chto takoe ideologiia? [What is ideology?]. Literaturnyi Sankt-Peterburg, no. 4 (31), July, pp. 1-2. [online] Available at: http://litgazeta.dompisatel.ru/archives/1398 [archived in WaybackMachine] (accessed 10.12.2018). (In Russ.).

Dal, V. I. (1996) Tolkovyi slovar' zhivogo velikorusskogo iazyka [Explanatory dictionary of the living great Russian language] : in 4 vols. St. Petersburg : Diamant LLC. Vol. 2. 784 p. (In Russ.).

Dionysius the Areopagite. (2003) Sochineniia. Tolkovaniia Maksima Ispovednika [Works. Maximus the Confessor's explanations]. St. Petersburg : Aleteiia Publ. 864 p. (In Russ.).

Zelinskii, S. A. (2008) Manipuliatsii massami i psikhoanaliz. Manipulirovanie massovymi psikhicheskimi protsessami posredstvom psikho-analiticheskikh metodik [Manipulations of masses and psychoanalysis. Manipulating mass psychic processes by psychoanalytical methods]. St. Petersburg : Publ. and Trading House "SKIFIIa". 248 p. (In Russ.).

Zolotarev, A. M. (1964) Rodovoi stroi i pervobytnaia mifologiia [Clan system and primitive mythology]. Moscow : Nauka Publ. 328 p. (In Russ.). 
Ivanov, V. V. (1978) Chet i nechet. Asimmetriia mozga i znakovykh sistem [Even and odd. Asymmetry of the brain and sign systems]. Moscow : Sovetskoe radio Publ. 184 p. (In Russ.).

Ivanov, V. V. (2004) Nauka o cheloveke: Vvedenie $v$ sovremennuiu antropologiiu [Science about man: Introduction into contemporary anthropology] : A lecture course. Moscow : RGGU Publ. 195 p. (In Russ.).

Ilinskiy, I. M. (2016) O «pravil'nom obrazovanii» dlia Rossii XXI veka [On a "proper education" for Russia in the 21st century]. Znanie. Ponimanie. Umenie, no. 3, pp. 5-31. (In Russ.). DOI: 10.17805/zpu.2016.3.1

Kabysh, I. A. (2007) Mezhdu Boldino i komp'iuterom [Between Boldino and computer]. Literaturnaia gazeta, no. 50 (6150), December 12-18, pp. 13. [online] Available at: http://www.lgz.ru/article/N50--6150---2007-12-12-/Mezhdu-Boldinoi-kompyyuterom2547/ [archived in WaybackMachine] (accessed 20.11.2018). (In Russ.).

Kara-Murza, S. G. (2002) Ideologiia i mat' ee nauka [Ideology and its mother science]. Moscow : Eksmo Publ. 256 p. (In Russ.).

Karmin, A, pp. (2011) Kul'turologiia [Culturology] : A textbook. 6th edn. St. Petersburg : Lan' Publ. ; Planeta muzyki Publ. 928 p. (In Russ.).

Cassirer, E. (2002) Filosofiia simvolicheskikh form [Philosophy of symbolic forms] : in 3 vols. Moscow ; St. Petersburg : Universitetskaia kniga Publ. Vol. 1: Iazyk [Language]. 272 p. (In Russ.).

Kolesov, V. V. (1998) Russkaia rech': vchera, segodnia, zavtra [Russian speech: Yesterday, today, tomorrow]. St. Petersburg : Iuna Publ. 248 p. (In Russ.).

Lévi-Strauss, C. (1978) Mif, ritual i genetika [Myth, ritual and genetics]. Priroda, no. 1, pp. 90-106. (In Russ.).

Leontiev, D. A. (2007) Psikhologiia smysla: priroda, stroenie i dinamika smyslovoi real'nosti [The psychology of sense: Nature, composition and dynamics]. 3rd edn., enlarged. Moscow : Smysl Publ. 511 p. (In Russ.).

Lukov, V. A. and Lukov, Vl. A. (2006) Teoriia tezaurusnogo podkhoda [Theory of the thesaurus approach]. In: Gumanitarnoe znanie : tendentsii razvitiia $\checkmark X X I$ veke [Humanities knowledge : Trends of development in the 21st century] / ed. by. V. A. Lukov. Moscow : National Institute of Business Publ. 680 p. Pp. 557-565. (In Russ.).

Lukov, V. A. and Lukov, Vl. A. (2008) Tezaurusy: sub"ektnaia organizatsiia gumanitarnogo znaniia [Thesauri: The subjective organization of humanities knowledge]. Moscow : National Institute of Business Publ. 784 p. (In Russ.).

Lukov, Vl. A. (2008) Sub"ektnaia kul'turologiia [Subjective culturology]. Elektronnyi zhurnal “Znanie. Ponimanie. Umenie”, no. 4. [online] Available at: http://www.zpu-journal.ru/e-zpu/2008/4/Lukov_culturology/ [archived in WaybackMachine] (accessed 20.11.2018). (In Russ.).

Meletinsky, E. M. (1998) Strukturno-tipologicheskoe izuchenie skazki [Structural and typological study of fairy tales]. In: Propp, V. Ya. Morfologiia $<$ volshebnoi> skazki. Istoricheskie korni volshebnoi skazki [The morphology of magic fairy tale. The historical roots of fairy tale]. Moscow : Labirint Publ. 512 p. Pp. 437-466. (In Russ.). 
Mendeleev, D. I. (2002) K poznaniiu Rossii [To the cognition of Russia]. Moscow : Airis-press Publ. 576 p. (In Russ.).

Mirovoi obshchestvennyi forum «Dialog tsivilizatsii» [World public forum "Dialogue of Civilizations"] (2013) : A manifesto. SSSR 2.0. [online] Available at: http://www.ussr-2.ru/index.php/sssr-2-0/dialog-tsivilizatsij/1637-mirovoj-obshchestvennyj-forum-dialog-tsivilizatsij-2013?showall=\&start=3 [archived in WaybackMachine] (accessed 20.11.2018). (In Russ.).

Mify narodov mira [Myths of the world's nations] (1980) : in 2 vols. / ed. by S. A. Tokarev. Moscow : Sovetskaia entsiklopediia Publ. Vol. I: A-K. 672 p. (In Russ.).

Nalimov, V. V. (1978) Nepreryvnost' protiv diskretnosti $v$ iazyke i myshlenii [Continuity versus discretion in language and thinking]. Tbilisi : Tbilisi University Publ. 84 p. (In Russ.).

Nalimov, V. V. (1989) Vozmozhno li uchenie o cheloveke v edinoi teorii znaniia? [Is a doctrine of man possible in the unified theory of knowledge?]. In: Chelovek $v$ sisteme nauk [Man in the system of sciences] / ed. by I. T. Frolov. Moscow : Nauka Publ. 504 p. Pp. 82-91. (In Russ.).

Nalimov, V. V. (2011) Spontannost' soznaniia. Veroiatnostnaia teoriia smyslov i smyslovaia arkhitektonika lichnosti [Spontaneity of consciousness. Probabilistic theory of senses and semantic architectonics of personality]. Moscow : Akademicheskii proekt Publ. ; Paradigma Publ. 399 p. (In Russ.).

Pamiatniki literatury Drevnei Rusi. Vtoraia polovina XVI veka [Monuments of literature of Ancient Russia. The second half of the 16th century] (1986) / introduction by D. S. Likhachev ; comp. and ed. by L. A. Dmitriev and D. S. Likhachev. Moscow : Khudozhestvennaia literatura Publ. 640, [4] p. (In Russ.).

Polanyi, M. (1985) Lichnostnoe znanie. Na puti k postkriticheskoi filosofii [Personal knowledge: Towards a post-critical philosophy]. Moscow : Progress Publ. 344 p. (In Russ.).

Prepodobnyi Iosif Volotskii [Saint Joseph Volotsky]. (1993) Prosvetitel' [The Enlightener]. Moscow : Spaso-Preobrazhensky Valaam Monastery Publ. 382 p. (In Russ.).

Printsipy opisaniia iazykov mira [Principles for the description of the world's languages]. (1976) Moscow : Nauka Publ. 343 p. (In Russ.).

Propp, V. Ya. (1928) Morfologiia skazki [Morphology of fairy tale]. Leningrad : Academia Publ. 152 p. (In Russ.).

Ricœur, P. (1995) Konflikt interpretatsii. Ocherki o germenevtike [The conflict of interpretations: Essays in hermeneutics]. Moscow : Medium Publ. 415 p. (In Russ.).

Sviridov, G. V. (2002) Muzyka kak sud'ba [Music as a fate]. Moscow : Molodaia gvardiia Publ. 798 p. (In Russ.).

Slavianskie drevnosti [Slavic antiquities] (1999) : An ethnological dictionary : in 5 vols. / ed. by N. I. Tolstoy. Moscow : Mezhdunarodnye otnosheniia Publ. Vol. 2: $D-K .697$, [1] p. (In Russ.).

Slovar' po kibernetike [Dictionary on cybernetics] (1979) / ed. by V. M. Glushkov. Kiev : Glavnaia redaktsiia Ukrainskoi sovetskoi entsiklopedii 
[The Chief Editorial Board of the Ukrainian Soviet Encyclopedia]. 623 p. (In Russ.).

Smirnova-Rosset, A. O. (2003) Zapiski [Notes]. Moscow : Zakharov Publ. 528 p. (In Russ.).

Stranitsy avtobiografii V. I. Vernadskogo [Pages of V. I. Vernadsky's autobiography] (1981) / V. I. Vernadsky ; comp. by N. V. Filippova. Moscow : Nauka Publ. 349 p. (In Russ.).

Stroev, S. A. (2013) Postindustrial'nyi simuliakr: dobro pozhalovat' v rolevuiu igru [Postindustrial simulacrum: Welcome to a role game]. Portal "Russkaia narodnaia liniia: informatsionno-analiticheskaia sluzhba”, December 17. [online] Available at: http://ruskline.ru/analitika/2013/12/17/postindustrialnyj_simulyakr_dobro_pozhalovat_v_rolevuyu_igru/ [archived in WaybackMachine] (accessed 20.11.2018). (In Russ.).

Toporov, V. N. (1982) Pervobytnye predstavleniia o mire (obshchii vzgliad) [A primitive vision of the world (The general view)]. In: Ocherki istorii estestvenno-nauchnykh znanii $v$ drevnosti [Sketches of the history of scientific knowledge in ancient times] / ed. by A. N. Shamin. Moscow : Nauka Publ. 278 p. Pp. 8-40. (In Russ.).

Trunov, D. G. (2000) Inoskazatel'naia priroda samootchuzhdeniia kak sotsiokul'turnogo fenomena [The allegoric nature of self-alienation as a sociocultural phenomenon] : Diss. ... Candidate of Philosophy. Perm. 139 p. (In Russ.).

Freud, S. (2007) Neudovletvorennost' kul'turoi [Civilization and its discontents]. In: Freud, S. Sobranie sochinenii [Collected works] : in 10 vols. Moscow : Firma STD LLC. Vol. 9. 607 p. Pp. 191-270. (In Russ.).

Heidegger, M. (1993) Vremia i bytie [Time and being] : Articles and addresses. Moscow : Respublika Publ. 447 p. (In Russ.).

Heidegger, M. (2006) Bytie i vremia[Being and time]. St. Petersburg : Nauka Publ. 452 p. (In Russ.).

Chernigovskaia, T. V. (2008) Iazyk i soznanie: chto delaet nas liud'mi? (Lektsiia, prochitannaia 20 noiabria 2008 g. v klube - literaturnom kafe Bilingua v ramkakh proekta «Publichnye lektsii Polit.ru») [Language and consciousness: What makes us human? (A lecture read on November 20, 2008 in the club - literary café Bilingua within the framework of "Public lectures at Polit.ru" project)]. Polit.ru, December 24. [online] Available at: https://polit.ru/article/2008/12/24/ langmind/ [archived in WaybackMachine] (accessed 20.11.2018). (In Russ.).

Eliade, M. (2000) Aspekty mifa [Aspects of myth]. Moscow : Akademicheskii proekt Publ. 222 p. (In Russ.).

Engels, F. (1982) Dialektika prirody [Dialectics of nature]. Moscow : Politizdat Publ. XVI, 359 p. (In Russ.). 
Горюнков Сергей Викторович - академик Международной академии социальных технологий, руководитель научно-исследовательского центра «Методологический переформат» Научного консорциума высоких гуманитарных и социальных технологий. Адрес: 197348, Россия, г. СанктПетербург, Богатырский пр., д. 7, корп. 3, кв. 261. Тел.: +7 (921) 338-86-23. Эл. адрес: RKC-alfa@mail.ru

Goryunkov Sergey Viktorovich, Member, International Academy of Social Technologies, Head, Research Centre "Methodological Reformat”, Scientific Consortium of High Humanitarian and Social Technologies. Postal address: Apt. 261, Bldg. 3, 7 Bogatyrskiy Prospekt, 197348 St. Petersburg, Russian Federation. Tel.: +7 (921) 338-86-23. E-mail: RKC-alfa@mail.ru

Для цุитирования:

Горюнков С. В. О проблемах изучения смысловой организации культуры [Электронный ресурс] // Горизонты гуманитарного знания. 2019. № 1. C. 131-162. URL: http://journals.mosgu.ru/ggz/article/view/955 (дата обращения: дд.мм.гггг). DOI: 10.17805/ggz.2019.1.8 